\title{
Zinc Oxide Whiskers with Intense Ultraviolet Emission
}

\author{
Hidetoshi SAITOH, Yusuke FUKADA and Shigeo OHSHIO \\ Department of Chemistry, Nagaoka University of Technology, 1603-1, Kamitomioka, Nagaoka-shi, Niigata 940-2188 \\ 強い紫外線発光を示す酸化亜鉛ウイスカー \\ 斎藤秀俊 $\cdot$ 深田祐介 · 大塩茂夫 \\ 長岡技術科学大学化学系, 940-2188 新潟県長岡市上富岡町 1603-1
}

\begin{abstract}
Well-organized $\mathrm{ZnO}$ whiskers were grown on the sapphire single crystalline substrate with a relatively high growth rate using the chemical-vapor-deposition technique. The $\mathrm{ZnO}$ whiskers showed ultraviolet emission on the photoluminescence and cathodoluminescence spectra. The intensity of the ultraviolet emission was comparable to the blue emission obtained from the commercial blue phosphor.
\end{abstract}

[Received November 5, 2002; Accepted December 19, 2002]

Key-words : Orientation, Whisker, $\mathrm{ZnO}, \mathrm{CVD}$, Photoluminescence, Cathodoluminescence, SEM

\section{Introduction}

The luminescence from $\mathrm{ZnO}$ crystallites is important in many technological photonic applications. $\mathrm{Zu}$ et al. reported room-temperature free exciton absorption and photoluminescence observed in $\mathrm{ZnO}$ thin films grown on sapphire substrates by a laser molecular beam epitaxy technique. ${ }^{1)}$ Ogata et al. obtained the $\mathrm{ZnO}$ films with a source gas combination of diethylzinc and nitrous oxide using metalorganic vapor phase epitaxy. The films maintained $c$-axis orientation and exhibited a bound exciton emission as well as a free exciton emission on the photoluminescence spectrum at $9 \mathrm{~K}^{2}{ }^{2}$ On the other hand, cathodoluminescence spectra were also evaluated from several samples. Sekiguchi et al. synthesized $\mathrm{ZnO}$ crystals using a flux method. They found that hydrogen plasma treatment strongly inhibited the green emission at $560 \mathrm{~nm}$ and promoted excitonic cathodoluminescence at $380 \mathrm{~nm}$ in $\mathrm{ZnO}^{3)}$ Haga et al. successfully prepared the $\mathrm{ZnO}$ films using remote-enhanced chemicalvapor-deposition (CVD) of diethylzinc and carbon dioxide. The cathodoluminescence spectrum consisted of a sharp band at $380 \mathrm{~nm}$ and a broad band centered at $560 \mathrm{~nm}^{4}$ ) These reports suggest that $\mathrm{ZnO}$ is thought to be an important candidate for applications to ultraviolet (UV) emitters and diode lasers.

We have developed a CVD apparatus in which operation is possible at atmospheric pressure. ${ }^{5), 6)}$ Fundamentally, this technique is thermal CVD. However, one major advantage is that the epitaxial growth of metal oxides at a high rate is possible. We already reported the formation of highly oriented $\mathrm{ZnO}$ whiskers formed on a (0001) sapphire single crystal by this CVD technique with zinc 2,4-pentanedionate, $\left.\mathrm{Zn}\left(\mathrm{C}_{5} \mathrm{H}_{7} \mathrm{O}_{2}\right)_{2} \cdot{ }^{7}{ }^{8} 8\right)$ The experimental $\mathrm{ZnO}$ whiskers of micrometer scale grow from the atomically flat surface of the single crystal. Therefore, all whiskers are perpendicularly oriented to the substrate. The whiskers have the following features: (1) the length and shape of the whiskers are almost uniform throughout the structure; (2) the growth rate of the whiskers remains constant with time; and (3) the epitaxial relationship between the whiskers and the substrate is determined to be $\mathrm{ZnO}[\overline{1010}](0001) / /$ sapphire $[\overline{1} 2 \overline{1} 0](0001)$. The structure of epitaxially grown whiskers may offer many possibilities for application in the fields of electronic and optical technologies.

Several applications on the $\mathrm{ZnO}$ whisker technology have been proposed up to now. For example, a new type of the ceramic field emitter was designed using the combination of the electrically conductive $\mathrm{Al}: \mathrm{ZnO}$ whisker with an extremely sharp tip and the amorphous carbon and related coating having relatively low work function. ${ }^{9)-11)}$ In addition, highly oriented europium-doped yttria $\left(\mathrm{Eu}: \mathrm{Y}_{2} \mathrm{O}_{3}\right.$ ) whiskers showing highly intensity of red photoluminescence were obtained using the atmospheric CVD technique. ${ }^{12}$ These results motivate us to use $\mathrm{ZnO}$ whiskers for obtaining intense UV emission. In this letter, the photoluminescence and cathodoluminescence properties of $\mathrm{ZnO}$ are described. Furthermore, defect-induced $\mathrm{ZnO}$ was also prepared by introducing $\mathrm{Al}$ incorporation into the $\mathrm{ZnO}$ whiskers. The luminescence intensities of these samples are compared.

\section{Experimental}

The single crystalline (0001) sapphire substrates were obtained from Dowa Co., and polished with a mis-cut value of within $0.1^{\circ}$. The substrate was cut into a size of $5 \times 10 \times$ $0.5 \mathrm{~mm}^{3}$ and then ultrasonically cleaned sequentially with trichloroethane, acetone, and methanol. After treatment, the single crystal was washed with deionized water for 30 minutes. On the (0001) sapphire substrate, having a lattice constant of $a_{0}=0.47587 \mathrm{~nm}$ at a temperature of $25^{\circ} \mathrm{C}, \mathrm{ZnO}$, having a lattice constant of $a_{0}=0.32497 \mathrm{~nm}$ at a temperature of $25^{\circ} \mathrm{C}$, grows along the $c$-axis with $\langle 0001\rangle$ orientation. There is a relatively large lattice mismatch of $31.7 \%$ between two crystals, when the crystalline direction of sapphire is parallel to that of $\mathrm{ZnO}$. However, regarding atomic configuration, the position of every 14 th zinc ion of $\mathrm{ZnO}$ overlaps with the position of every 11 th oxide ion of sapphire with a lattice mismatch of less than $0.4 \%$, by the $30^{\circ}$ rotation of $\mathrm{ZnO}$ relative to sapphire in the $c$-plane. Therefore, the $30^{\circ}$ rotational epitaxy of $\mathrm{ZnO}$ whiskers is expected.

$\mathrm{ZnO}$ whiskers were prepared using an atmospheric CVD apparatus that was previously employed in obtaining epitaxial anatase films, ${ }^{5}$ ) with titanium tetra-isopropoxide as the source complex. The reactant, $\mathrm{Zn}\left(\mathrm{C}_{5} \mathrm{H}_{7} \mathrm{O}_{2}\right)_{2}$ (Soekawa Chemical Co., quoted purity of $99.9 \%$ ), was loaded into a vaporizer and vaporized using an electric heater. In order to synthesize $\mathrm{Al}: \mathrm{ZnO}$ whiskers, $\mathrm{Al}\left(\mathrm{C}_{5} \mathrm{H}_{7} \mathrm{O}_{2}\right)_{3}$ (Soekawa Chemical Co., quoted purity of $99.9 \%$ ), was also loaded into the vaporizer. The amount of doping of $\mathrm{Al}$ was changed with the amount of $\mathrm{Al}\left(\mathrm{C}_{5} \mathrm{H}_{7} \mathrm{O}_{2}\right)_{3}$ loaded into the vaporizer. The inside temperature of the vaporizer measured using a $K$ type thermocouple is defined as the vaporizing temperature. The reactant vapor was first carried by nitrogen gas flowing at a rate of $1.2 \mathrm{dm}^{3} / \mathrm{min}$ and then sprayed from the metallic 
nozzle directly onto the single crystalline (0001) sapphire substrate mounted on the electric heater. The surface temperature measured using the $K$-type thermocouple is defined as the substrate temperature. The reactant vapor, $\mathrm{Zn}\left(\mathrm{C}_{5} \mathrm{H}_{7} \mathrm{O}_{2}\right)_{2}$, was immediately decomposed by the heat from the substrate heater to form whiskers. The deposition duration of $\mathrm{ZnO}$ was maintained between 60 and 90 min for each experiment using a metallic shutter placed below the nozzle. The substrate was heated to $550^{\circ} \mathrm{C}$ using the electric heater. The distance between the nozzle and the substrate was maintained at $15 \mathrm{~mm}$ throughout the experiments.

The metal composition of the samples was determined using inductive coupled plasma-atomic emission spectroscopy (ICP-AES) with a spectrometer, SPS-400, Seiko Instruments Co. The surface morphology and the cathodoluminescence spectrum of the sample were measured at room temperature using a scanning electron microscope (SEM; T-300, JEOL with a cathodoluminescence spectrometer). The photoluminescence spectrum of the sample was also obtained room temperature using a spectrometer (FP 6500DS, JASCO Co.). Transmission electron microscopy (TEM; using JEM-2010F, JEOL) was also conducted.

\section{Results and discussion}

In this experiment, not only non-doped $\mathrm{ZnO}$ whiskers but alsowhisker samples with $0.5,0.8$ and $2.0 \mathrm{~mol} \% \mathrm{Al}$ were synthesized. Note that the samples for $\mathrm{Al}$ doping evaluation were dissolved into acid solution. Therefore, the Al doping evaluation was carried out after cathodoluminescence measurement. Figure 1 shows a set of SEM images of the specimens obtained with growth durations of 90,75 and $60 \mathrm{~min}$. A series of growths were performed at various amounts of doped $\mathrm{Al}$ ranging from 0 to $2.0 \mathrm{~mol} \%$. Typical SEM images were taken of the center region of each sample synthesized for the SEM observation. For the non-doped $\mathrm{ZnO}$ whiskers as shown in (a), a whisker diameter of approximately 2.5 $\mu \mathrm{m}$ and a whisker length of approximately $27 \mu \mathrm{m}$ were observed, implying an aspect ration of 10.8. The number density of the whiskers was $9 \times 10^{4} \mathrm{~mm}^{-2}$. These values were unchanged with the concentration of Al. For the $0.8 \mathrm{~mol} \%$ $\mathrm{Al}: \mathrm{ZnO}$ and $2.0 \mathrm{~mol} \% \mathrm{Al}: \mathrm{ZnO}$ whiskers, the whisker length was reduced to $22 \mu \mathrm{m}$ and $17 \mu \mathrm{m}$ as shown in (b) and (c), respectively, while the diameter and the density unchanged. The epitaxial relationship between the whisker and the substrate has already discussed in Ref. 13). Figure 2 shows the TEM image of the intrinsic $\mathrm{ZnO}$ whisker cut in round slice. The lattice image shows no disturbance of the atomic order. The free exciton luminescence or UV emission is emitted at room temperature from the $\mathrm{ZnO}$ crystal with high atomic ordering. ${ }^{1)}$

Figure 3 shows the photoluminescence properties for $\mathrm{ZnO}$ and $\mathrm{Al}: \mathrm{ZnO}$ whiskers grown on the sapphire substrate. The spectra were obtained from the typical $\mathrm{ZnO}$ whisker and several Al-doped samples at room temperature, where the $258 \mathrm{~nm}$ line of the normal UV radiation lamp was used as an excitation source. For the $\mathrm{ZnO}$ whiskers, the main features of the photoluminescence spectra can be divide into three categories: dominant emission at UV region, low energy tail extending from the dominant emission and a weak violetblue peak. The dominant emission peak is identified as the I9 line at $390 \mathrm{~nm} .{ }^{14)}$ This line has previously assigned to the recombination of excitons bound to neutral donors or acceptors. ${ }^{15)}$ For the $\mathrm{Al}: \mathrm{ZnO}$ whiskers, a broad emission was seen around $410 \mathrm{~nm}$, superimposed to the long emission tail of the near band edge emission. The intensity of the dominant emission obtained from the $\mathrm{ZnO}$ whiskers decreased with incorporation of $\mathrm{Al}$ into the whisker, suggesting that the UV emission was attributable to that obtained from ordered crystalline configuration.
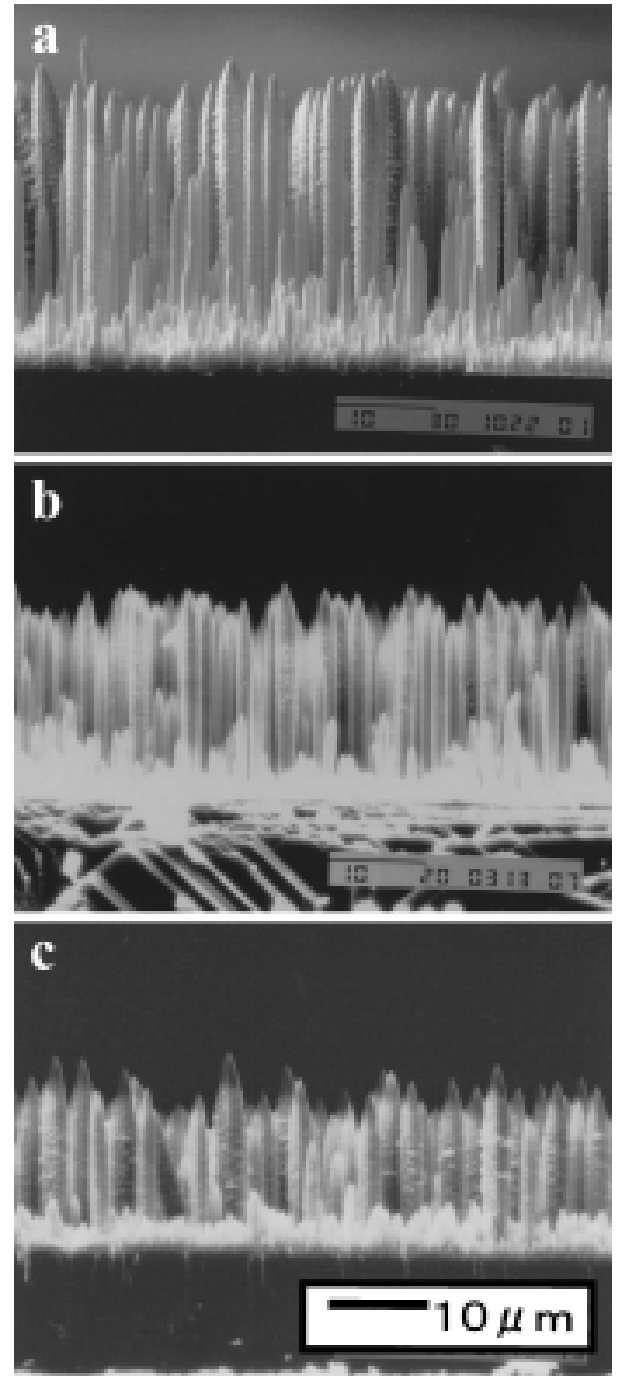

Fig. 1. A set of SEM images of the specimens obtained with growth durations of (a) $90 \mathrm{~min}$, (b) $75 \mathrm{~min}$ and (c) $60 \mathrm{~min}$. The concentration of $\mathrm{Al}$ is $0.5 \mathrm{~mol} \%, 0.8 \mathrm{~mol} \%$ and $2.0 \mathrm{~mol} \%$ for samples (a), (b) and (c), respectively.

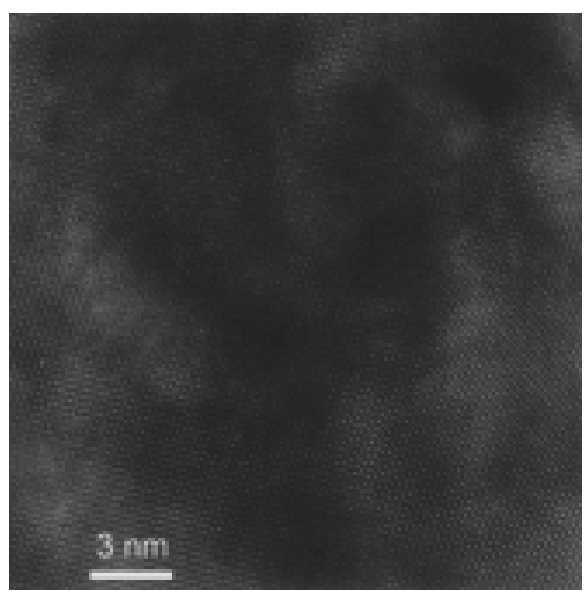

Fig. 2. TEM images of intrinsic $\mathrm{ZnO}$ whisker cut in round slice.

The cathodoluminescence spectra of the $\mathrm{ZnO}$ whisker and several Al-doped samples at room temperature, where the electron beam at an accelerating voltage of $30 \mathrm{keV}$, used as 


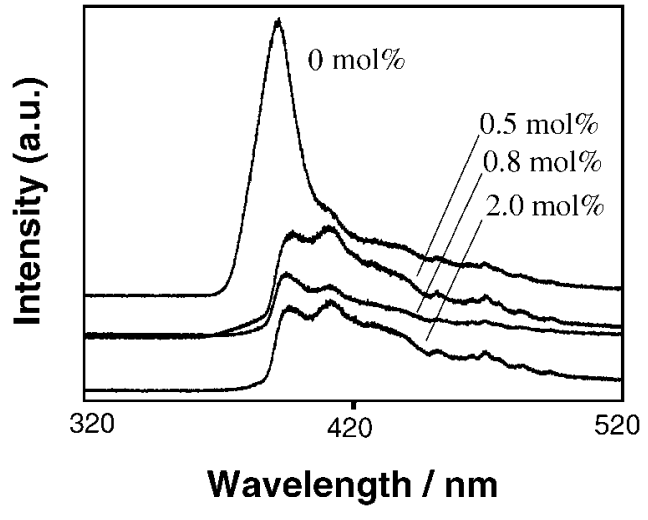

Fig. 3. Photoluminescence properties for $\mathrm{ZnO}$ and $\mathrm{Al}: \mathrm{ZnO}$ whiskers grown on the sapphire substrate.

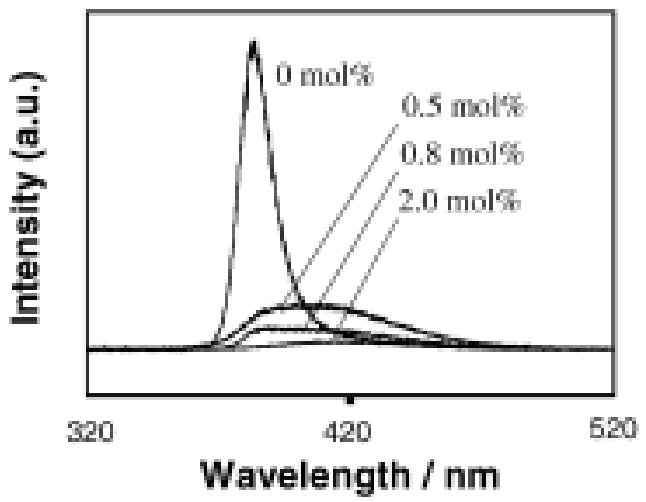

Fig. 4. Cathodoluminescence properties for $\mathrm{ZnO}$ and $\mathrm{Al}: \mathrm{ZnO}$ whiskers grown on the sapphire substrate.

an excitation source are shown in Fig. 4. The spectrum has a strong peak that is attributable to the band edge luminescence at $379 \mathrm{~nm}$ and a low energy tail extending from the main emission. A broad emission around $560 \mathrm{~nm}$ which is so-called green emission was not seen at any samples. With the increase of the Al concentration, the intensity of UV luminescence significantly decreases. In contrast, the broad peak around $410 \mathrm{~nm}$ appeared. The $410 \mathrm{~nm}$ emission is very weak and 10-30 times less than that of the band edge emission. It is noted that the broad emission might be assigned to the donor-acceptor recombination induced by the incorporation of Al. This is consistent with the photoluminescence property. However, for accurate identification, further investigation is needed.

The results of the photoluminescence and cathodoluminescence spectra indicate that high crystalline ordering is obtained in the non-doped $\mathrm{ZnO}$ whisker. Figure 5 indicates the cathodoluminescence spectra of the non-doped $\mathrm{ZnO}$ whiskers and the commercial blue phosphor. The commercial blue phosphor is the crystalline particles of $\mathrm{BaMgAl}_{10} \mathrm{O}_{17}: \mathrm{Eu}$, obtained from Nicha Chemical Co. This indicates very intense visible blue emission. The intensities of these two samples are placed on the same sample holder in the cathodoluminescence spectrometer and compared each other. The peak intensity of the UV emission obtained from the $\mathrm{ZnO}$ whiskers is comparable to that obtained from the commercial blue phosphor.

\section{Conclusion}

The well-organized $\mathrm{ZnO}$ and $\mathrm{Al}: \mathrm{ZnO}$ whiskers were prepared on the (0001) sapphire single crystal by the

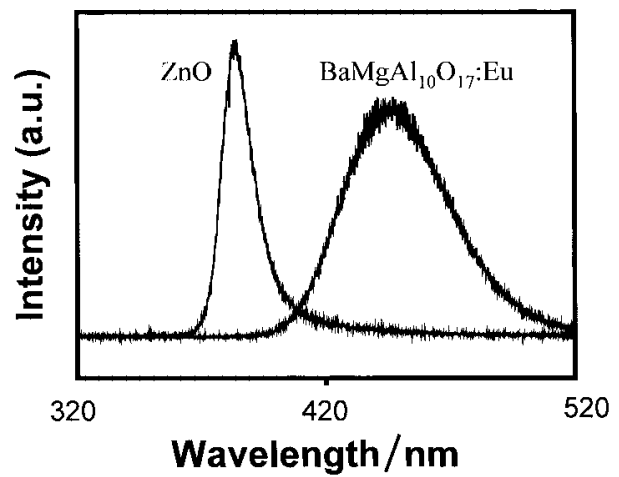

Fig. 5. Cathodoluminescence of $\mathrm{ZnO}$ whisker and $\mathrm{BaMgAl}_{10} \mathrm{O}_{17}$ : Eu blue phosphor.

atmospheric CVD technique. The photoluminescence and cathodoluminscence spectra obtained from the $\mathrm{ZnO}$ whiskers had the structure consisted of the dominant UV emission, the low energy tail extending from the UV emission and the weak violet-blue peak. With the increase of the Al concentration, the intensity of the UV emission significantly decreases. In contrast, the violet-blue peak around $410 \mathrm{~nm}$ appeared. The peak intensity of the UV emission obtained from the $\mathrm{ZnO}$ whiskers is comparable to that obtained from the commercial blue phosphor.

Acknowledgments The authors thank to JEOL Co., Ltd. for TEM operation. This study partially supported by 21 st century COE program at Nagaoka University of Technology.

\section{References}

1) Zu, P., Tang, Z. K., Wong, G. K. L., Kawasaki, M., Ohtomo, A., Koinuma, H. and Segawa, Y., Solid State Commun., Vol. 103, pp. 459-463 (1997).

2) Ogata, K., Kim, S.-W., Fujita, Sz. and Fujita, Sg., J. Cryst. Growth, Vol. 240, pp. 112-116 (2002).

3) Sekiguchi, T., Ohashi, N. and Terada, Y., Jpn. J. Appl. Phys., Vol. 36, L289-L291 (1997)

4) Haga, K., Kamidaira, M., Kashiwaba, Y., Sekiguchi, T. and Watanabe, H., J. Cryst. Growth, Vol. 214/215, pp. 77-80 (2000).

5) Tanaka, N., Ohshio, S. and Saitoh, H., J. Ceram. Soc. Japan, Vol. 105, pp. 551-555 (1997).

6) Saitoh, H., Sunayama, H., Tanaka, N. and Ohshio, S., J. Ceram. Soc. Japan, Vol. 106, pp. 1051-1055 (1998).

7) Satoh, M., Tanaka, N., Ueda, Y., Ohshio, S. and Saitoh, H., Jpn. J. Appl. Phys., Vol. 38, L586-L589 (1999).

8) Saitoh, H., Satoh, M., Tanaka, N., Ueda, Y. and Ohshio, S., Jpn. J. Appl. Phys., Vol. 38, pp. 6873-6877 (1999).

9) Ohkawara, Y., Naijo, T., Washio, T., Ohshio, S., Ito, H. and Saitoh, H., Jpn. J. Appl. Phys., Vol. 40, pp. 7013-7017 (2001).

10) Ohkawara, Y., Akasaka, H., Namiki, K. C., Ohshio, S., Ito, H. and Saitoh. H., Jpn. J. Appl. Phys., in press.

11) Washio, T., Ohkawara, Y., Ohshio, S., Ito, H. and Saitoh, H., New Diam. Frontier Carbon Technol., Vol. 12, pp. 157-160 (2002).

12) Satoh, Y., Ohshio, S. and Saitoh, H., Jpn. J. Appl. Phys., Vol. 41, pp. L1250-L1252 (2002).

13) Saitoh, H., Namioka, Y., Sugata, H. and Ohshio, S., Jpn. J. Appl. Phys., Vol. 40, pp. 6024-6028 (2001).

14) Bagnall, D. M., Chen, Y. F., Shen, M. Y., Zhu, Z., Goto, T. and Yao, T., J. Cryst. Growth, Vol. 184/185, pp. 605-609 (1998).

15) Reynolds, D. C., Look, D. C., Jogai, J., Litton, C. W., Collins, T. C., Harsch, W. and Cantwell, G., Phys. Rev. B, Vol. 57, pp. 12151-12155 (1998) 